\title{
Reduction of Carbon Impurities in Aluminum Nitride from Time- Resolved Chemical Vapor Deposition Using Trimethylaluminum
}

\author{
Polla Rouf,* Pitsiri Sukkaew, Lars Ojamäe, and Henrik Pedersen
}

Cite This: J. Phys. Chem. C 2020, 124, 14176-14181

Read Online

ABSTRACT: Aluminum nitride (AlN) is a semiconductor with a wide range of applications from light-emitting diodes to high-frequency transistors. Electronic grade AlN is routinely deposited at $1000{ }^{\circ} \mathrm{C}$ by chemical vapor deposition (CVD) using trimethylaluminum (TMA) and $\mathrm{NH}_{3}$, while low-temperature CVD routes to high-quality AlN are scarce and suffer from high levels of carbon impurities in the film. We report on an atomic layer deposition-like CVD approach with time-resolved precursor supply where readsorption of methyl groups from the AlN surface is suppressed by the addition of an extra pulse, $\mathrm{H}_{2}, \mathrm{~N}_{2}$, or $\mathrm{Ar}$, between the TMA and $\mathrm{NH}_{3}$ pulses. The suppressed readsorption allowed deposition of AlN films with a carbon content of 1 at. $\%$ at $480{ }^{\circ} \mathrm{C}$. Kinetic and quantum-chemical modeling suggests that the extra pulse between TMA and $\mathrm{NH}_{3}$ prevents readsorption of desorbing methyl groups

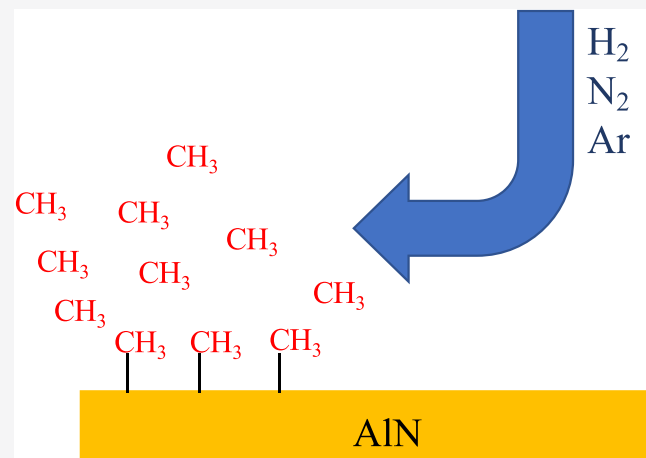
terminating the AlN surface after the TMA pulse.

\section{INTRODUCTION}

Aluminum nitride (AIN) is a widely used semiconductor material in several electronic devices ${ }^{1}$ because of its direct wide band gap of $6.2 \mathrm{eV}^{2}$ A conventional method for depositing epitaxial films of AlN is chemical vapor deposition (CVD) using trimethylaluminum (TMA), $\mathrm{Al}_{2}\left(\mathrm{CH}_{3}\right)_{6}$, and ammonia, $\mathrm{NH}_{3}$, at temperatures, typically, above $1000{ }^{\circ} \mathrm{C}$. ${ }^{3}$ This limits the applications of AlN to substrates and underlying film materials that can withstand such temperatures. An alternative low-temperature deposition route is atomic layer deposition (ALD), which is a time-resolved form of CVD where the $\mathrm{Al}$ and $\mathrm{N}$ precursors are pulsed into the deposition chamber sequentially, separated by inert gas pulses. This gas pulsing makes the process solely depend on surface chemical reactions and omits gas-phase chemical reactions, which typically need high temperatures. ALD of AlN has previously been reported using TMA with $\mathrm{NH}_{3}$ via thermal, ${ }^{4-6} \mathrm{NH}_{3}$ plasma, ${ }^{7-10}$ and $\mathrm{N}_{2}$ plasma ${ }^{11}$ routes. Plasma processes can lead to crystalline and conformal AlN films at temperatures $<300{ }^{\circ} \mathrm{C}$. ${ }^{9,10}$ To obtain a crystalline AlN film via the thermal route, a temperature $>375$ ${ }^{\circ} \mathrm{C}$ is needed. ${ }^{5,6}$

The TMA molecule is reported to decompose above 330 ${ }^{\circ} \mathrm{C}^{12}$ by breaking one of the $\mathrm{Al}-\mathrm{C}$ bonds, forming dimethyl aluminum and a methyl group at temperatures $\leq 500{ }^{\circ} \mathrm{C}$. ${ }^{13}$ Thermal ALD of AlN typically contains 5-10 at. \% C depending on the deposition temperature, ${ }^{4,6}$ making thermal ALD routes not ideal for depositing electronic grade AlN. Plasma ALD is also associated with high levels of carbon impurities as atomic hydrogen, produced in the plasma discharge, can induce a chemistry trapping carbon impurities in the film by abstracting $\mathrm{H}_{2}$ from surface methyl groups. ${ }^{14}$ Deposition of crystalline AlN with low levels of carbon is thus dependent on an efficient carbon-cleaning surface chemistry.

Herein, we report a low-temperature, ALD-like CVD approach depositing AlN using TMA and $\mathrm{NH}_{3}$ delivered in separate pulses at $480{ }^{\circ} \mathrm{C}$. We show that adding an extra gas pulse, with the gas flow perpendicular to the substrate surface between the TMA and $\mathrm{NH}_{3}$ pulses, leads to a drastic decrease in the $\mathrm{C}$ content and increases the crystalline quality of the films. Quantum chemical density functional theory (DFT) and kinetic modeling suggest that the lower carbon content in the films is attributed to the prevented readsorption of methyl groups to the AlN surface.

\section{METHODS}

Film Deposition. The AlN films were deposited in a Picosun R-200 ALD system with a base pressure of $400 \mathrm{~Pa}$ and continuous $\mathrm{N}_{2}$ (99.999\%, further purified with a getter filter to remove moisture) flow through the deposition chamber. The chamber walls and the substrate holder were heated using separate heating systems. $\mathrm{Si}(100)$ wafers without further cleaning were cut into $15 \times 15 \mathrm{~mm}^{2}$ pieces and used as

Received: February 27, 2020

Revised: June 1, 2020

Published: June 5, 2020 

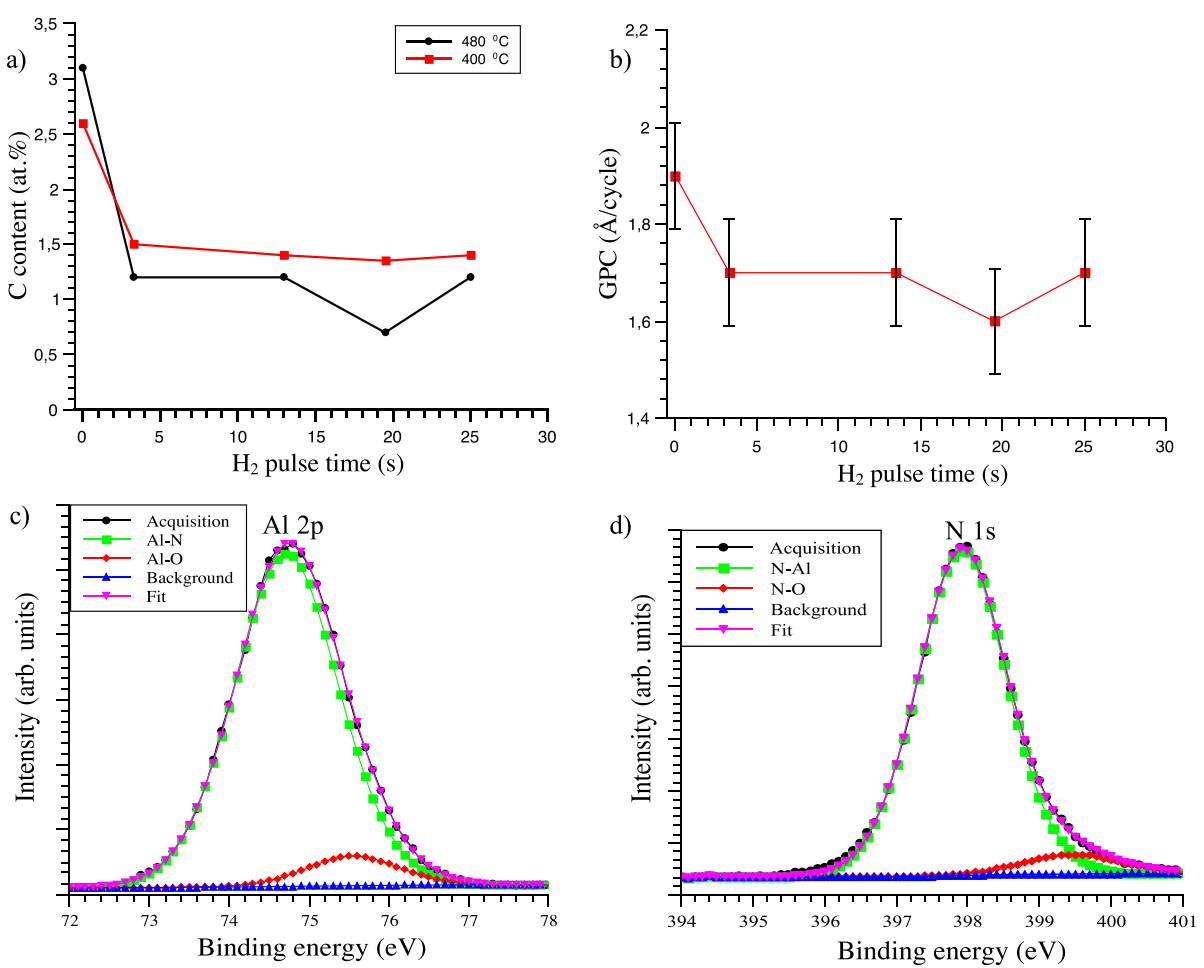

Figure 1. (a) XPS measurement of the films with different pulse lengths of $\mathrm{H}_{2}$ showing a decreasing $\mathrm{C}$ content upon increasing the $\mathrm{H}_{2}$ pulse time. (b) Growth per cycle of the films with different $\mathrm{H}_{2}$ pulse times deposited at $480{ }^{\circ} \mathrm{C}$. The high-resolution XPS of AlN with a $19.5 \mathrm{~s} \mathrm{H}_{2}$ pulse deposited at $480{ }^{\circ} \mathrm{C}(\mathrm{c}) \mathrm{Al} 2 \mathrm{p}$ and $(\mathrm{d}) \mathrm{N} 1 \mathrm{~s}$.

substrates. The substrates were loaded into the deposition chamber without using a load-lock. Commercially available TMA (Pegasus Ltd., Alpha grade) in a stainless-steel bubbler was used at room temperature with $100 \mathrm{sccm} \mathrm{N}_{2}$ as the carrier gas. $\mathrm{NH}_{3}$ (AGA/Linde, 99.999\%) was used as the nitrogen source in the process. The TMA pulse time was set at $0.1 \mathrm{~s}$ with a $6 \mathrm{~s}$ purge and the $\mathrm{NH}_{3}$ pulse time was set to $12 \mathrm{~s}$ with a $6 \mathrm{~s}$ purge unless otherwise stated. $\mathrm{H}_{2}$ (99.999\%, further purified with a getter filter to remove moisture), $\mathrm{N}_{2}$, or $\mathrm{Ar}$ (99.999\%, further purified with a getter filter to remove moisture) was used as a cleaning pulse between the TMA and $\mathrm{NH}_{3}$ pulses. It should be noted that the flow of these cleaning pulses $(150 \mathrm{sccm})$ was perpendicular to the substrate surface and horizontal for the purge pulses. The difference between the cleaning pulse and the purge, besides the flow direction, is also the flow rate where the purge gas $\left(\mathrm{N}_{2}\right)$ had a total flow of $500 \mathrm{sccm}$ (continuous flow into the reaction chamber) distributed over the six precursor gas channels, where five gas lines had a flow of $60 \mathrm{sccm}$ and one line, acting as the main $\mathrm{N}_{2}$ line into the chamber, had a flow of $200 \mathrm{sccm}$. However, the cleaning pulse had a flow of $150 \mathrm{sccm}$ independent of the gas used, and the gas channel used was located above the chamber.

Characterization. The crystallinity of the deposited films was studied using a PANalytical EMPYREAN MRD X-ray diffractometer with a $\mathrm{Cu}$-anode $\mathrm{X}$-ray tube and a 5 -axis $(x-y$ - $z$ $v$-u) sample stage in the grazing-incidence X-ray diffraction (GIXRD) configuration with a $0.5^{\circ}$ incident angle. A PANalytical $\mathrm{X}^{\prime}$ Pert PRO with a $\mathrm{Cu}$-anode tube and BraggBrentano HD optics was used for $\theta-2 \theta$ measurement and in the $\mathrm{X}$-ray reflectivity (XRR) mode to measure the thickness of the films. From the XRR measurements, the software PANalytical $\mathrm{X}^{\prime}$ Pert reflectivity was used to fit the data using a two-layer model, AlN/substrate. A LEO 1550 scanning electron microscope with an acceleration energy of $10-20 \mathrm{kV}$ was used to study the morphology of the films. Kratos AXIS Ultra DLD X-ray photoelectron spectroscopy (XPS) equipped with Ar sputtering was used to analyze the composition (5\% error margin of the atomic percentage) and chemical environments in the films. The composition of the films was obtained after clean sputtering the surface with an Ar beam energy of $0.5 \mathrm{keV}$ and a sputtering area of $3 \mathrm{~mm}^{2}$ for $600 \mathrm{~s}$. CasaXPS software was used to evaluate the data. Gaussian-Laurentius functions and Shirley background were used to fit the experimental XPS data.

Computational Details. Quantum chemical DFT computations were applied to study the mechanism of surface desorption of methyl groups on the AlN surface. The calculations were performed using the Perdew-BurkeErnzerhof ${ }^{15,16}$ generalized gradient approximation functional together with the Grimme D3-empirical dispersion correction $^{17}$ using the Vienna $\mathrm{Ab}$ initio Simulation Package (VASP). ${ }^{18}$ For the representation of pseudopotentials for $\mathrm{Al}$, $\mathrm{N}, \mathrm{C}$, and $\mathrm{H}$, the projected augmented wave method $\mathrm{d}^{19,20}$ provided by that package was used, where in the surface studies, a fractional charge of $0.75^{21,22}$ was used for the $\mathrm{H}$ atoms bonded to the $\mathrm{N}$ atoms at the bottom (opposite side)terminated surface layer to facilitate the saturation of dangling bonds. The hexagonal unit cell of the bulk AlN structure was first derived by energy minimization with respect to the lattice parameters and coordinates using a $7 \times 7 \times 7$ grid of $\gamma$ centered $k$-points, resulting in $a=3.114 \AA$ and $c=4.995 \AA$. Previous experimental determination of the lattice parameters shows that $a=3.11131 \AA$ and $c=4.98079 \AA$, which correlate well with the DFT calculations. ${ }^{23}$ Then, a model of a twodimensional surface was constructed by cutting out a slab of 


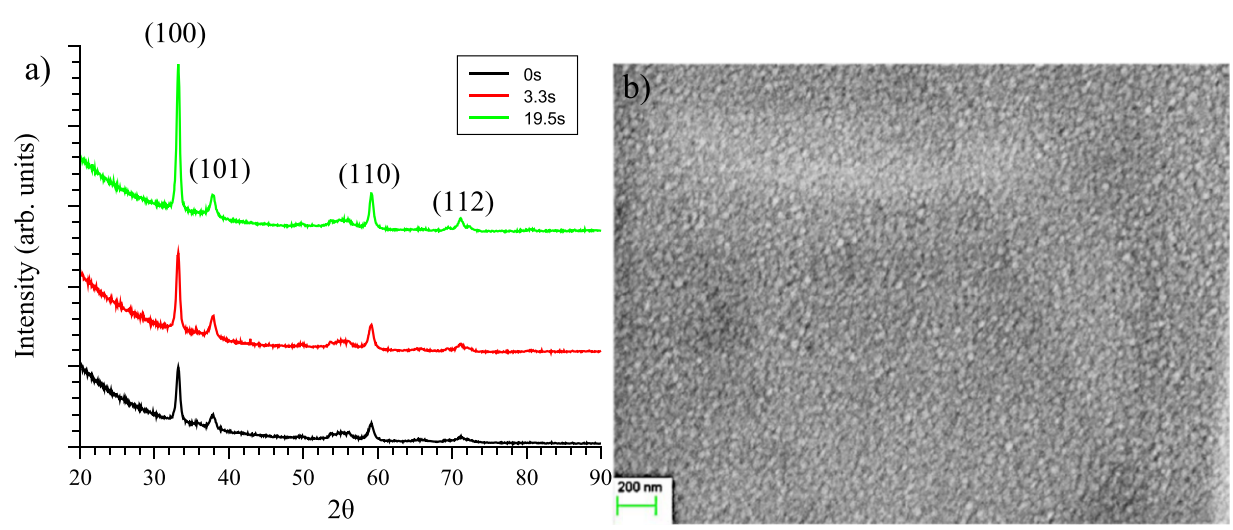

Figure 2. (a) GIXRD of the films deposited at $480^{\circ} \mathrm{C}$ on $\mathrm{Si}(100)$ with different lengths of the $\mathrm{H}_{2}$ pulse between the TMA and $\mathrm{NH}_{3}$ pulses showing crystalline, hexagonal AlN where the crystallinity increases upon longer $\mathrm{H}_{2}$ pulse. (b) Top-view SEM of the AlN film deposited at $480{ }^{\circ} \mathrm{C}$ with a $19.5 \mathrm{~s} \mathrm{H}_{2}$ pulse.

five $(\mathrm{Al}, \mathrm{N})$ layers orthogonal to the $c$-direction (corresponding to a vertical height of about $10.6 \AA$ from a "top" Al to a "bottom" $\mathrm{N}$ ), with a hexagonal surface (two-dimensional) unit cell with $a_{\text {surf }}=3.114 \AA$ (and with the direction of the $c$-axis reversed compared to the crystal cell $c$-axis) (see Figure $S 1$ ). The length of the $c$-axis was increased to $40.0 \AA$ to create empty space between the slabs. A cell with the surface cell axes ( $a_{\text {surf }}, b_{\text {surf }}$, where $\left.b_{\text {surf }}=a_{\text {surf }}\right)$ doubled was used in the calculations, which led to four $\mathrm{Al}$ atoms (or "surface sites") with a dangling bond that can be saturated by $\mathrm{CH}_{3}$ being present at the topmost surface. The atomic coordinates of the slabs (with or without adsorbents) were geometry optimized using a $3 \times 3 \times 1 k$-point grid. Free energies were calculated from the computed vibrational mode frequencies of the optimized structures $^{24}$ (Table S1).

The kinetics of the surface adsorption and desorption processes were simulated based on the quantum chemical results. The adsorption rate was approximated from the impingement $\operatorname{rate}^{25,26}$ as no tight transition state is present along the internal reaction coordinate. The reverse reaction rates were derived based on the forward reaction rates to ensure that the thermodynamic equilibria can be reached as enough time has passed. The DFT-based surface reaction rates together with the gas-phase reaction mechanism and the rate for $\mathrm{C}_{2} \mathrm{H}_{6}$ formation from $\mathrm{CH}_{3}$ from the literature ${ }^{27-31}$ were employed in the kinetic model. The simulation of the kinetics was performed using the MATLAB SimBiology module. ${ }^{32,33}$ The simulations of the amount of surface species as a function of time start from the surface fully covered by methyl groups $\left(4 \mathrm{CH}_{3}(\mathrm{~s})\right)$ at a pressure of $100 \mathrm{~Pa}$ and a temperature of $773 \mathrm{~K}$. The pressure was held constant by the presence of noninteracting gas molecules (e.g., $\mathrm{N}_{2}$ ) plus molecules formed after desorption. The number of gas molecules was assumed to be much larger than the number of surface sites; that is, the initial molar ratio of gas molecules $/ \mathrm{CH}_{3}(\mathrm{~s})$ was set to 50 . Two kinetic models are considered here. In the first model, the methyl radicals produced from the reactions are assumed to be completely purged away from the system at all times (i.e., by setting their adsorption rate to zero) similar to when $\mathrm{H}_{2}, \mathrm{~N}_{2}$, or Ar is introduced between the TMA and $\mathrm{NH}_{3}$ pulses in the ALD cycle, while in the second model, no extra pulse is used; that is, no extra pulse between TMA and $\mathrm{NH}_{3}$ is assumed.

\section{RESULTS AND DISCUSSION}

In initial experiments, $\mathrm{H}_{2}$ pulses of different lengths were added between the TMA and $\mathrm{NH}_{3}$ pulses. Without addition of $\mathrm{H}_{2}$ pulses, the $\mathrm{C}$ content in an AlN film deposited at $480{ }^{\circ} \mathrm{C}$ was measured to be 3.1 at. \% from XPS analysis. Addition of a $\mathrm{H}_{2}$ pulse decreased the $\mathrm{C}$ content (Figure 1a). A short $\mathrm{H}_{2}$ pulse of $3.3 \mathrm{~s}$ decreases the $\mathrm{C}$ content to around 1 at. \%. The carbon content is found to be at this low level also for longer durations of the $\mathrm{H}_{2}$ pulse. The same trend was also observed for a deposition temperature of $400{ }^{\circ} \mathrm{C}$ (Figure 1a). However, for depositions made at $400{ }^{\circ} \mathrm{C}$, the carbon content is slightly lower without the $\mathrm{H}_{2}$ pulse (2.6 at. \%) as compared to $480{ }^{\circ} \mathrm{C}$ and the amount of carbon decreases to about 1.5 at. \% with the addition of $\mathrm{H} \mathrm{H}_{2}$ pulse. The growth per cycle (GPC) of the AlN films is stable upon increasing the length of the $\mathrm{H}_{2}$ pulse (Figure 1b). A slight decrease in the growth per cycle with increasing length of the $\mathrm{H}_{2}$ pulse could be observed. The composition obtained from XPS of the film deposited at 480 ${ }^{\circ} \mathrm{C}$ with a $19.5 \mathrm{~s} \mathrm{H}_{2}$ pulse was 49.1 at. $\% \mathrm{Al}, 46.0$ at. $\% \mathrm{~N}, 4.3$ at. \% $\mathrm{O}$, and 0.6 at. \% $\mathrm{C}$, which gives an $\mathrm{Al} / \mathrm{N}$ ratio of 1.07 . High-resolution XPS spectra for $\mathrm{Al} 2 \mathrm{p}$ were fitted with two subpeaks at 74.7 and $75.5 \mathrm{eV}$ attributed to $\mathrm{Al}-\mathrm{N}$ and $\mathrm{Al}-\mathrm{O}$ bonds, respectively (Figure 1c). For N 1s, the two subpeaks were positioned at 397.9 and $399.4 \mathrm{eV}$ and were attributed to $\mathrm{N}-\mathrm{Al}$ and $\mathrm{N}-\mathrm{O}$ bonds, respectively (Figure $1 \mathrm{~d}$ ). The $\mathrm{O} 1 \mathrm{~s}$ spectra show the $\mathrm{O}-\mathrm{N}$ and $\mathrm{O}-\mathrm{Al}$ bonds (Figure $\mathrm{S} 2$ ). The fitted peaks for $\mathrm{Al} 2 \mathrm{p}$ and $\mathrm{N}$ 1s are in line with previous XPS measurements on the AlN films. ${ }^{34}$

GIXRD measurement shows that the films consist of polycrystalline, hexagonal $\mathrm{AlN}$ and that the crystallinity of the films increases with the time for the $\mathrm{H}_{2}$ pulses, as it is seen that the intensity of the (100) plane is more than thrice when $\mathrm{H}_{2}$ is added (black line) compared to that without addition of $\mathrm{H}_{2}$ (red line) (Figure 2a). The full width at half-maximum value (fwhm) for the (100) plane also decreases from 0.657 to $0.503^{\circ}$ upon addition of the $\mathrm{H}_{2}$ pulse, indicating a higher degree of crystallinity. This shows that adding a $\mathrm{H}_{2}$ pulse not only decreases the carbon content in the film but also increases the crystallinity. By using the Debye-Scherrer equation, an approximate crystallite size of $17 \mathrm{~nm}$ was calculated using the fwhm of the AlN (100) peak for $19.5 \mathrm{H}_{2}$ exposure. Figure $2 \mathrm{~b}$ shows the morphology of the fine-grained polycrystalline nature of the AlN film with a $19.5 \mathrm{~s} \mathrm{H}_{2}$ pulse deposited at 480 ${ }^{\circ} \mathrm{C}$, which was also seen from the GIXRD measurement (Figure 2a). The crystallite size calculated from XRD correlates 
well with the top-view scanning electron microscopy (SEM) image.

To test if the reduction in the carbon content was due to a surface chemical reaction between the surface methyl groups and the hydrogen gas, $\mathrm{N}_{2}$ and Ar were also tested as purge gases between the TMA and $\mathrm{NH}_{3}$ pulses. The pulse time for $\mathrm{H}_{2}, \mathrm{~N}_{2}$, and Ar was kept constant at 19.5 s. XPS measurements show that the carbon content in the films is $1 \pm 0.4$ at. \% independent of the gas used. This suggests that carbon reduction by the added pulse between TMA and $\mathrm{NH}_{3}$ is not a chemical-cleaning pulse but rather acts to prevent the readsorption of carbon-containing species from the surface. Interestingly, the different gases used influence the crystallinity of the films. GIXRD measurements of the films deposited with $\mathrm{H}_{2}, \mathrm{~N}_{2}$, and Ar show that the intensity of the (100) plane decreases when going from $\mathrm{H}_{2}$ to $\mathrm{N}_{2}$ and to Ar (Figure 3). $\theta-$

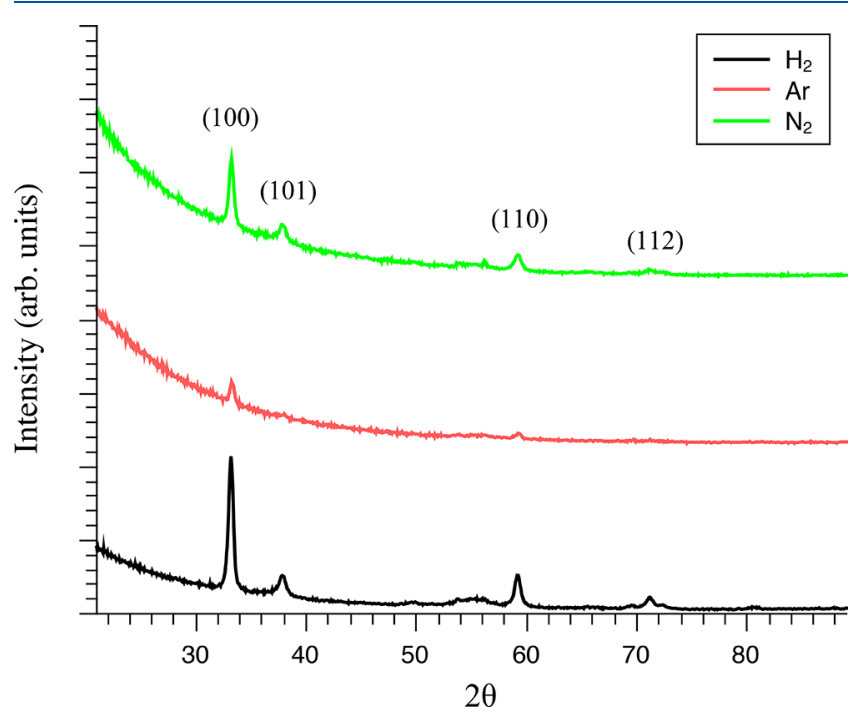

Figure 3. GIXRD of the films on $\mathrm{Si}(100)$ with $\mathrm{H}_{2}, \mathrm{Ar}$, and $\mathrm{N}_{2}$ as an extra pulse between the TMA and $\mathrm{NH}_{3}$ pulses deposited at $480{ }^{\circ} \mathrm{C}$.
$2 \theta$ showed the same trend (Figure S3). Also, the composition of the AlN film changes when different gases were used where higher $\mathrm{O}$ impurities were detected for $\mathrm{N}_{2}$ and $\mathrm{Ar}$ than for $\mathrm{H}_{2}$. When $\mathrm{N}_{2}$ and Ar were used, 5.2 and 5.5 at. \% $\mathrm{O}$ were detected compared to 4.3 at. \% when $\mathrm{H}_{2}$ was used. The $\mathrm{Al} / \mathrm{N}$ ratio was 1.07 when $\mathrm{H}_{2}$ was used, while the ratios were 1.13 and 1.16 when $\mathrm{N}_{2}$ and Ar were used, respectively. We speculate that the hydrogen pulse acts to scavenge oxygen from the film surface and that this, together with a higher thermal conductivity of $\mathrm{H}_{2}$ $\left(0.182 \mu \mathrm{W} \mathrm{m}{ }^{-1} \mathrm{deg}^{-1}\right)$ compared to those of $\mathrm{N}_{2}(0.0268 \mu \mathrm{W}$ $\left.\mathrm{m}^{-1} \mathrm{deg}^{-1}\right)$ and $\operatorname{Ar}\left(0.0185 \mu \mathrm{W} \mathrm{m}{ }^{-1} \mathrm{deg}^{-1}\right)$, could explain the better crystallinity observed when $\mathrm{H}_{2}$ was used compared to $\mathrm{N}_{2}$ and $\mathrm{Ar}^{35}$ The higher crystallinity observed when $\mathrm{N}_{2}$ was used, compared to that when Ar was used, is then ascribed to the higher thermal conductivity of $\mathrm{N}_{2}$ compared to that of Ar.

Kinetic simulations were used to obtain an atomistic level understanding of the surface chemistry (Figure 4). Starting from a fully saturated surface (i.e., in the model, four $\mathrm{CH}_{3}$ groups at four surface sites), the first methyl group is seen to quickly desorb from the fully occupied surface. This could be expected because the desorption of $\mathrm{CH}_{3}$ from a fully occupied surface is actually exergonic (and with a negligible reaction barrier), see Table S1, which is likely due to the repulsion between the closely packed surface-adsorbed methyl groups. The general trend is that the desorption barriers become significantly higher with an increasing number of empty sites on the surface. This is to be expected because the repulsion between the adsorbed groups decreases as the number of empty sites increases for the most densely packed surfaces. Figure 4a shows the kinetics when a pulse of inert gas is added between TMA and $\mathrm{NH}_{3}$. Adding an extra pulse between the TMA and $\mathrm{NH}_{3}$ pulses will remove the methyl radicals from above the surface, which facilitates a more accelerated decrease of the carbon group surface coverage by suppressing the readsorption process. With no added pulse of the inert gas between TMA and $\mathrm{NH}_{3}$ (Figure 4b), the methyl groups previously released from the surface can either become readsorbed on the empty sites or converted to $\mathrm{C}_{2} \mathrm{H}_{6}$ molecules, which is manifested by the persistence of the dominantly $\mathrm{CH}_{3}-$ terminated surface in Figure $4 \mathrm{~b}$.
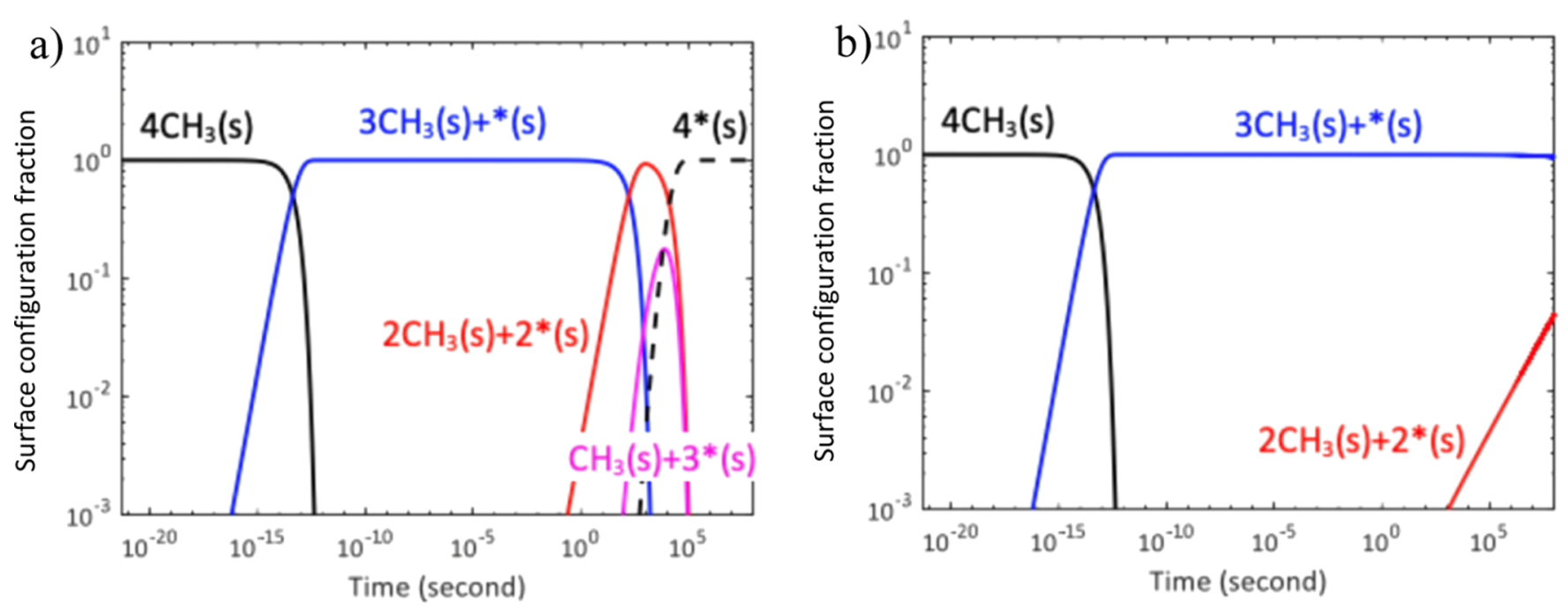

Figure 4. Simulated surface configuration fractions as a function of time, (a) with a pulse of inert gas between $\mathrm{TMA}$ and $\mathrm{NH}_{3}$ and $(\mathrm{b})$ without a pulse of inert gas between TMA and $\mathrm{NH}_{3}$, at $100 \mathrm{~Pa}$ and $500{ }^{\circ} \mathrm{C}$. The label " $4 \mathrm{CH}_{3}(\mathrm{~s})$ " implies that there are four adsorbed $\mathrm{CH}_{3}$ in the surface unit cell, whereas " $3 \mathrm{CH}_{3}(\mathrm{~s})+*(\mathrm{~s})$ " implies three adsorbed $\mathrm{CH}_{3}$ and one surface vacancy and so forth. 

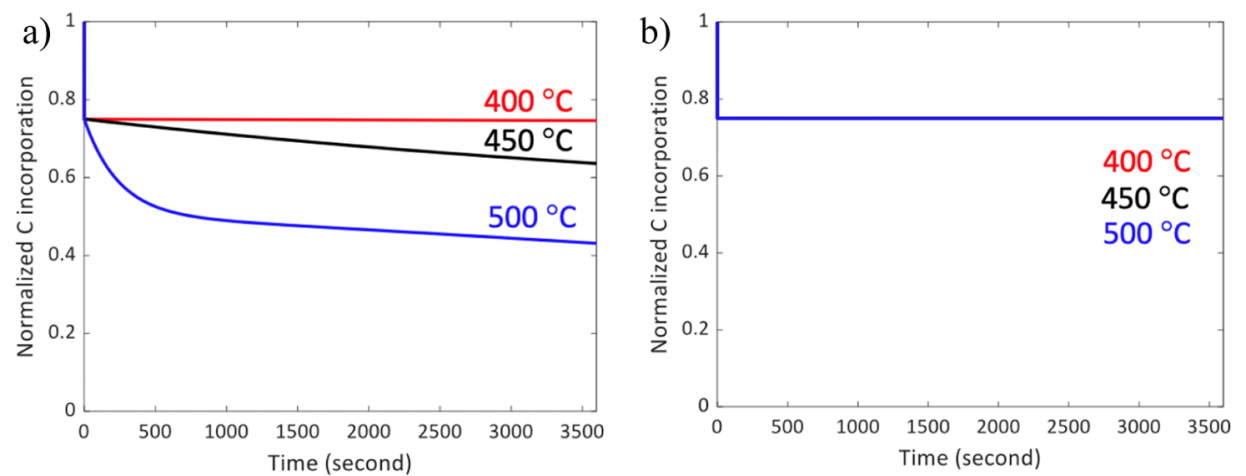

Figure 5. Simulations of time-dependent carbon incorporation at 400,450 , and $500{ }^{\circ} \mathrm{C}$ with a pulse of inert gas between $\mathrm{TMA}$ and $\mathrm{NH}_{3}(\mathrm{a})$ and without the inert gas pulse (b).

The carbon incorporation in the film versus time as estimated from the computed surface coverage is shown in Figure 5. The readsorption process leads to a significant increase in the carbon incorporation in the film (Figure 5b). On the other hand, when a pulse is introduced between TMA and $\mathrm{NH}_{3}$, the readsorption process is suppressed, resulting in the reduction of the carbon incorporation in the film (Figure 5a). This correlates with the experimental results in Figure 1a. Increasing temperature was also found to decrease the amount of carbon at the surface when a cleaning pulse is applied (Figure 5a). The same trend has previously been shown on $\mathrm{Al}_{2} \mathrm{O}_{3}$, where higher temperature decreases the amount of surface methyl groups. ${ }^{36}$

We suggest that the extra pulse between TMA and $\mathrm{NH}_{3}$ assists in the diffusion of desorbed methyl groups away from the AlN surface and prevents their readsorption. In the kinetic simulations (Figure S4), the methyl groups on the surface desorb quickly and after a short time these methyl groups react and form ethane $\left(\mathrm{C}_{2} \mathrm{H}_{6}\right)$. This would facilitate a faster elimination of the carbon groups by suppressing the readsorption pathway according to our kinetic model. Without the extra gas pulse, the desorbed surface methyl groups could readsorb before $\mathrm{NH}_{3}$ is introduced into the chamber, which could lead them to be trapped in the film. Carbon impurities in semiconductor-grade materials are a problem, typically, when deposited at high temperature, and we believe that this $\mathrm{ABC}$ type pulsed process (where A is the TMA pulse, B is the extra pulse, and $\mathrm{C}$ is the $\mathrm{NH}_{3}$ pulse) could possibly be a solution to accomplish high-temperature ALD films with low $\mathrm{C}$ impurities.

\section{SUMMARY AND CONCLUSIONS}

A high-temperature thermal ALD-like CVD approach with time-resolved precursor supply for AlN was explored by adding an extra pulse of $\mathrm{H}_{2}, \mathrm{~N}_{2}$, or Ar between the TMA and $\mathrm{NH}_{3}$ pulses to investigate if that could change the surface chemistry and lower the carbon content in the film. We show that by adding an extra purge gas pulse perpendicular to the substrate surface, the carbon impurities in the film decreased drastically to approximately 1 at. \% giving an $\mathrm{Al} / \mathrm{N}$ ratio of 1.07 . The surface chemistry and the role of the extra pulse between TMA and $\mathrm{NH}_{3}$ were investigated with quantum chemical and kinetic modeling. It was found from the modeling that the most loosely bound surface methyl groups can desorb within the experimental time frame. The added pulse between TMA and $\mathrm{NH}_{3}$ is, therefore, believed to clean the region just above the surface from methyl groups by suppressing any readsorption of the desorbed methyl groups. It was found from the calculations that the amount of surface methyl groups decreases with increasing temperature. The growth of the AlN film was somewhat dependent on the extra pulse time, where longer pulses gave a smaller growth rate, which were attributed to less carbon impurities in the film. The type of gas used as a pulse between TMA and $\mathrm{NH}_{3}$ was found to have a stronger impact on the crystallinity, where the crystallinity of the films increased when going from $\mathrm{Ar}, \mathrm{N}_{2}$, to $\mathrm{H}_{2}$, which is ascribed to the thermal conductivity of the gases.

\section{ASSOCIATED CONTENT}

\section{Supporting Information}

The Supporting Information is available free of charge at https://pubs.acs.org/doi/10.1021/acs.jpcc.0c01724.

Slab of AlN used in the calculations showing 25\% coverage of the $\mathrm{Al}$ sites with $\mathrm{CH}_{3}$, computed reaction electronic energies $\Delta \mathrm{E}$ and reaction Gibbs free energies $\Delta \mathrm{G}^{\circ}$ for the removal of a $\mathrm{CH}_{3}$ molecule from an $\mathrm{Al}$ terminated AlN surface fully or partially covered by $\mathrm{CH}_{3}$ in a surface unit cell with four reaction sites, O 1s XPS measurements, theta-2theta of the films on $\mathrm{Si}$ (100), and results from the kinetic simulations (PDF)

\section{AUTHOR INFORMATION}

\section{Corresponding Author}

Polla Rouf - Department of Physics, Chemistry and Biology, Linköping University, SE-581 83 Linköping, Sweden; 이이.org/0000-0002-1452-4548; Email: polla.rouf@liu.se

\section{Authors}

Pitsiri Sukkaew - Department of Physics, Chemistry and Biology, Linköping University, SE-581 83 Linköping, Sweden; (1) orcid.org/0000-0002-6175-1815

Lars Ojamäe - Department of Physics, Chemistry and Biology, Linköping University, SE-581 83 Linköping, Sweden; C orcid.org/0000-0002-5341-2637

Henrik Pedersen - Department of Physics, Chemistry and Biology, Linköping University, SE-581 83 Linköping, Sweden; (1) orcid.org/0000-0002-7171-5383

Complete contact information is available at:

https://pubs.acs.org/10.1021/acs.jpcc.0c01724

\section{Notes}

The authors declare no competing financial interest. 


\section{ACKNOWLEDGMENTS}

This project was supported by the Swedish Foundation for Strategic Research (SSF) through the project "time-resolved low temperature CVD for III-nitrides" (SSF-RMA 15-0018). L.O. acknowledges financial support from the Swedish Government Strategic Research Area in Materials Science on Functional Materials at Linköping University (Faculty grant SFO Mat LiU no. 2009 00971) and from the Swedish Research Council (VR). Supercomputing resources were provided by the Swedish National Supercomputer Centre (NSC) via the Swedish National Infrastructure for Computing (SNIC).

\section{REFERENCES}

(1) Taniyasu, Y.; Kasu, M.; Makimoto, T. An Aluminium Nitride Light-Emitting Diode with a Wavelength of 210 Nanometres. Nature 2006, 441, 325-328.

(2) Li, J.; Nam, K. B.; Nakarmi, M. L.; Lin, J. Y.; Jiang, H. X.; Carrier, P.; Wei, S.-H. Band Structure and Fundamental Optical Transitions in Wurtzite AlN. Appl. Phys. Lett. 2003, 83, 5163-5165.

(3) Chen, Z.; Newman, S.; Brown, D.; Chung, R.; Keller, S.; Mishra, U. K.; Denbaars, S. P.; Nakamura, S. High Quality AlN Grown on SiC by Metal Organic Chemical Vapor Deposition. Appl. Phys. Lett. 2008, 93, 191906.

(4) Van Bui, H.; Nguyen, M. D.; Wiggers, F. B.; Aarnink, A. A. I.; De Jong, M. P.; Kovalgin, A. Y. Self-Limiting Growth and Thickness- And Temperature- Dependence of Optical Constants of ALD AlN Thin Films. ECS J. Solid State Sci. Technol. 2014, 3, P101-P106.

(5) Liu, X.; Ramanathan, S.; Lee, E.; Seidel, T. E. Atomic Layer Deposition of Aluminum Nitride Thin Films from Trimethyl Aluminum (TMA) and Ammonia. MRS Proc. 2004, 811, 11.

(6) Riihelä, D.; Ritala, M.; Matero, R.; Leskelä, M.; Jokinen, J.; Haussalo, P. Low temperature deposition of AIN films by an alternate supply of trimethyl aluminum and ammonia. Chem. Vap. Depos. 1996, 2, 277-283.

(7) Dendooven, J.; Deduytsche, D.; Musschoot, J.; Vanmeirhaeghe, R. L.; Detavernier, C. Conformality of $\mathrm{Al}_{2} \mathrm{O}_{3}$ and AlN Deposited by Plasma-Enhanced Atomic Layer Deposition. J. Electrochem. Soc. 2010, 157, G111.

(8) Ozgit, C.; Donmez, I.; Alevli, M.; Biyikli, N. Self-Limiting LowTemperature Growth of Crystalline AlN Thin Films by PlasmaEnhanced Atomic Layer Deposition. Thin Solid Films 2012, 520, 2750-2755.

(9) Ozgit-Akgun, C.; Goldenberg, E.; Okyay, A. K.; Biyikli, N. Hollow Cathode Plasma-Assisted Atomic Layer Deposition of Crystalline AlN, GaN and $\mathrm{Al}_{\mathrm{x}} \mathrm{Ga}_{1-\mathrm{x}} \mathrm{N}$ Thin Films at Low Temperatures. J. Mater. Chem. C 2014, 2, 2123-2136.

(10) Bosund, M.; Sajavaara, T.; Laitinen, M.; Huhtio, T.; Putkonen, M.; Airaksinen, V.-M.; Lipsanen, H. Properties of AlN Grown by Plasma Enhanced Atomic Layer Deposition. Appl. Surf. Sci. 2011, 257, $7827-7830$.

(11) Nepal, N.; Qadri, S. B.; Hite, J. K.; Mahadik, N. A.; Mastro, M. A.; Eddy, C. R. Epitaxial Growth of AlN Films via Plasma-Assisted Atomic Layer Epitaxy. Appl. Phys. Lett. 2013, 103, 082110.

(12) Yamashita, S.; Watanuki, K.; Ishii, H.; Shiba, Y.; Kitano, M.; Shirai, Y.; Sugawa, S.; Ohmi, T. Dependence of the Decomposition of Trimethylaluminum on Oxygen Concentration. J. Electrochem. Soc. 2011, 158, H93.

(13) Zhang, Z.; Pan, Y.; Yang, J.; Jiang, Z.; Fang, H. Experimental Study of Trimethyl Aluminum Decomposition. J. Cryst. Growth 2017, 473, 6-10.

(14) Erwin, S. C.; Lyons, J. L. Atomic Layer Epitaxy of Aluminum Nitride: Unraveling the Connection between Hydrogen Plasma and Carbon Contamination. ACS Appl. Mater. Interfaces 2018, 10, 2014220149.

(15) Perdew, J. P.; Burke, K.; Ernzerhof, M. Generalized Gradient Approximation Made Simple. Phys. Rev. Lett. 1996, 77, 3865-3868.
(16) Perdew, J. P.; Burke, K.; Ernzerhof, M. Erratum: Generalized Gradient Approximation Made Simple. Phys. Rev. Lett. 1997, 78, 1396.

(17) Grimme, S.; Antony, J.; Ehrlich, S.; Krieg, H. A Consistent and Accurate Ab Initio Parametrization of Density Functional Dispersion Correction (DFT-D) for the 94 Elements H-Pu. J. Chem. Phys. 2010, 132, 154104.

(18) Kresse, G.; Furthmüller, J. Efficient iterative schemes forab initiototal-energy calculations using a plane-wave basis set. Phys. Rev. B: Condens. Matter Mater. Phys. 1996, 54, 11169-11186.

(19) Blöchl, P. E. Projector Augmented-Wave Method. Phys. Rev. B 1994, 50, 17953-17979.

(20) Kresse, G.; Joubert, D. From Ultrasoft Pseudopotentials to the Projector Augmented-Wave Method. Phys. Rev. B: Condens. Matter Mater. Phys. 1999, 59, 1758-1775.

(21) Shiraishi, K. A New Slab Model Approach for Electronic Structure Calculation of Polar Semiconductor Surface. J. Phys. Soc. Jpn. 1990, 59, 3455-3458.

(22) Dai, J.; Song, Y. First Principles Calculations on the Hydrogen Atom Passivation of $\mathrm{TiO}_{2}$ Nanotubes. RSC Adv. 2016, 6, 1919019198.

(23) Nilsson, D.; Janzén, E.; Kakanakova-Georgieva, A. Lattice Parameters of AlN Bulk, Homoepitaxial and Heteroepitaxial Material. J. Phys. D: Appl. Phys. 2016, 49, 175108.

(24) McQuarrie, D. A.; Simon, J. D. Molecular Thermodynamics; University Science Books, 1999.

(25) Sukkaew, P.; Kalered, E.; Janzén, E.; Kordina, O.; Danielsson, Öa.; Ojamäe, L. Growth Mechanism of $\mathrm{SiC}$ Chemical Vapor Deposition: Adsorption and Surface Reactions of Active Si Species. J. Phys. Chem. C 2018, 122, 648-661.

(26) Sukkaew, P.; Danielsson, Ö.; Ojamäe, L. Growth Mechanism of SiC CVD: Surface Etching by H2, H Atoms, and HCl. J. Phys. Chem. A 2018, 122, 2503-2512.

(27) Baulch, D. L.; Cobos, C. J.; Cox, R. A.; Esser, C.; Frank, P.; Just, T.; Kerr, J. A.; Pilling, M. J.; Troe, J.; Walker, R. W.; et al. Evaluated Kinetic Data for Combustion Modelling. J. Phys. Chem. Ref. Data 1992, 21, 411-734.

(28) Baulch, D. L.; Cobos, C. J.; Cox, R. A.; Esser, C.; Frank, P.; Just, T.; Kerr, J. A.; Pilling, M. J.; Troe, J.; Walker, R. W.; et al. Evaluated Kinetic Data for Combustion Modelling. J. Phys. Chem. Ref. Data 1992, 21, 411-734.

(29) Pintassilgo, C. D.; Loureiro, J.; Cernogora, G.; Touzeau, M. Methane decomposition and active nitrogen in a N2-CH4glow discharge at low pressures. Plasma Sources Sci. Technol. 1999, 8, 463478.

(30) Baulch, D. L.; Cobos, C. J.; Cox, R. A.; Frank, P.; Hayman, G.; Just, T.; Kerr, J. A.; Murrells, T.; Pilling, M. J.; Troe, J.; et al. Evaluated Kinetic Data for Combustion Modeling. Supplement I. J. Phys. Chem. Ref. Data 1994, 23, 847-848.

(31) NIST Chemistry WebBook, SRD69 https://webbook.nist.gov/ chemistry/form-ser/ (accessed November 21, 2019).

(32) MATLAB R2015a; The MathWorks Inc.: Natick, MA, USA, 2015.

(33) Erdtman, E.; Andersson, M.; Lloyd Spetz, A.; Ojamäe, L. Simulations of the thermodynamics and kinetics of $\mathrm{NH} 3$ at the $\mathrm{RuO}$ 2 (110) surface. Surf. Sci. 2017, 656, 77-85.

(34) Motamedi, P.; Cadien, K. XPS analysis of AlN thin films deposited by plasma enhanced atomic layer deposition. Appl. Surf. Sci. 2014, 315, 104-109.

(35) Saxena, S. C.; Gupta, G. P. Thermal Conductivity. Thermal Conductivity of Binary, Ternary and Quaternary Mixtures of Polyatomic Gases; Flynn, R. D., Peavy, A. B., Jr., Eds.; Gaithersburg, Maryland, 1967; pp 605-613.

(36) Vandalon, V.; Erwin) Kessels, W. M. M. Revisiting the Growth Mechanism of Atomic Layer Deposition of Al 2 O 3: A Vibrational Sum-Frequency Generation Study. J. Vac. Sci. Technol., A 2017, 35, $05 \mathrm{C} 313$. 